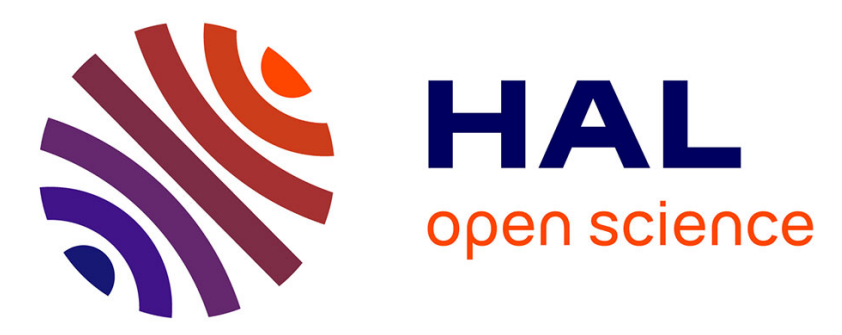

\title{
Ergonomics of the control by a quadriplegic of hand functions
}

Wafa Tigra, Christine Azevedo Coste, Charles Fattal, David Guiraud

\section{To cite this version:}

Wafa Tigra, Christine Azevedo Coste, Charles Fattal, David Guiraud. Ergonomics of the control by a quadriplegic of hand functions. NER 2015 - 7th International IEEE/EMBS Conference on Neural Engineering, Apr 2015, Montpellier, France. pp.759-762, 10.1109/NER.2015.7146734 . lirmm01276002

\section{HAL Id: lirmm-01276002 https://hal-lirmm.ccsd.cnrs.fr/lirmm-01276002}

Submitted on 18 Feb 2016

HAL is a multi-disciplinary open access archive for the deposit and dissemination of scientific research documents, whether they are published or not. The documents may come from teaching and research institutions in France or abroad, or from public or private research centers.
L'archive ouverte pluridisciplinaire HAL, est destinée au dépôt et à la diffusion de documents scientifiques de niveau recherche, publiés ou non, émanant des établissements d'enseignement et de recherche français ou étrangers, des laboratoires publics ou privés. 


\title{
Ergonomics of the control by a quadriplegic of hand functions
}

\author{
Wafa Tigra ${ }^{1}$, Christine Azevedo Coste $^{1}$ IEEE, member, Charles Fattal ${ }^{2}$, David Guiraud ${ }^{1}$ IEEE EMBS, member
}

\begin{abstract}
In subjects with complete Spinal Cord Injury (SCI) above C7, the four limbs are paralyzed (quadriplegia). Recovery of grasping movements is then reported as a priority. Indeed, most activities of daily living are achieved through upper limbs. Thus, restoration of hand and forearm active mobility could significantly increase independence and quality of life of these people and decrease their need of human aid. Although most of the subjects plebiscite pharmacological or biological solutions, only orthotics and Functional Electrical Stimulation (FES) allow, so far, to restore hand movements but they are rarely used. Limited ergonomics and comfort of piloting modes could partly explain the low usage of these systems. In this context, our aim is to explore possible solutions for subjects to interact with such devices. In this article, we propose to evaluate the capacity of active upper limb muscles contraction to be used to intuitively control FES in tetraplegic subjects. In this study, we assessed the ability to gradually contract different muscles: trapezius, deltoid, platysma and biceps. Three subjects with $\mathrm{C} 6$ to $\mathrm{C} 7$ neurological levels of lesion were included. We show that over the active upper limb muscles tested, contraction of the trapezius muscle was considered by the subjects as the most comfortable and could be employed as an intuitive mode of control of functional assistive devices.
\end{abstract}

\section{INTRODUCTION}

lien Prevalence of spinal cord injuries (SCI) continues to increase and although technical aids (passive braces, wheelchairs,...) allow to give back some independence, inability of quadriplegic subjects to perform grip movements strongly limits their quality of life. Recovery of grasping movements is reported as a priority [1]. In recent decades, surgical procedures such as muscle-tendon transfers or, more recently, nerve transfers have been proposed to regain mobility of the arm and hand after several weeks of rehabilitation. However, these two methods require the presence of enough muscles or nerves under voluntary control to restore the required movement. Presently, in the absence of enough voluntary active muscles and nerves, only active orthotics or devices using FES allow to restore hand movements. They have been used for over 25 years in rehabilitation centers. Spasticity and muscular atrophy are decreased, and limb mobilization is improved when using such assistive devices [2]. One main challenge in this context is to provide the subject with an interface to allow him/her to interact with the system. Indeed, the subject has to control the action of the assistive device voluntarily. Controlling the system has to be as natural as possible and allowing the user to obtain a quality hand opening and closing as well as an

\footnotetext{
${ }^{1}$ DEMAR LIRMM, Université Montpellier II - INRIA, 161 rue Ada, 34392 Montpellier, France. Firstname. Lastnamed lirmm. fr

${ }^{2}$ Propara Center, Montpellier, France
}

increase in strength during grasping. User should also be able to hold his hand at a desired position and select different gripping modes. Various interfaces have been tested in the past: joysticks, joint movement detection, switches, breath control, electromyography (EMG) signals among others. In [3] voluntary wrist extension is used as mode control. A wrist osseointegrated Hall effect sensor implant serves for FES hand neuroprosthesis. Nevertheless, wrist extension is limited to subjects who have a below C6 injury. Obviously, control interfaces are highly dependent on the subject's level of injury and remaining voluntary activity. The use of EMG signals from muscles under voluntary control proves to be an alternative because whatever their level of injury, each subject should be able to contract some muscles. Dietz et al. proposed to use surface EMG from deltoid muscle of contralateral arm to pilot a device which stimulates hand muscles [4]. In [5] the EMG signal from ipsilateral wrist extensor muscles is used to pilot a hand neuroprosthesis. An implanted device [6] uses shoulder and neck muscles to control the FES applied to arm and hand muscles. EMG signals are also used to control an upper limb exosqueleton in [7]. The aim of the work we present here is to evaluate the capacity and comfort of gradually contracting upper limb muscles ipsi- and contralaterally for $\mathrm{C} 6-\mathrm{C} 7$ tetraplegic subjects in order to serve as interface for a device allowing to recover prehension movements.

\section{Materials And Methods}

\section{A. Subjects}

Experiments were performed on 3 quadriplegic male subjects, who have a complete motor injury. Subject 1 is 33 years old, C6 and is paralyzed since 4 years. Subject 2 is 35 years old, C7 and is paralyzed since 13 years and has just sustained a muscle-tendon transfer. Subject 3 is 21 years old, C7 and is paralyzed since 6 months, all are AIS A. An information note explaining the purpose of the study was delivered and an informed consent obtained. The study was conducted at Propara neurological rehabilitation center (Montpellier, France) during scheduled clinical assessments. The studied muscles are: right and left superior trapezius, right and left middle deltoid, right and left biceps and right and left platysma for the subject 2 . Superior trapezius, middle deltoid, biceps and platysma muscles of the ispilateral side of the dominant (right) upper limb were studied for the subjects 1 and 3.

\section{B. Materials}

Signals were recorded using an insulated National Instrument acquisition card NI USB 6218, 32 inputs, 16-bit 
(National Instruments, USA). BIOVISION EMG amplifiers (Wherheim, Germany) were used, the gain was fixed to 1000 . The acquisition card was connected to a portable computer running on batteries. The acquisition is done at $2 \mathrm{kHz}$. EMG data is filtered (high pass filter: $20 \mathrm{~Hz}$, fourfolder butterworth filter, 0 phase) and RMS values calculated. Surface ECG BIOTRACE Electrodes (Controle graphique S.A, France) were used.

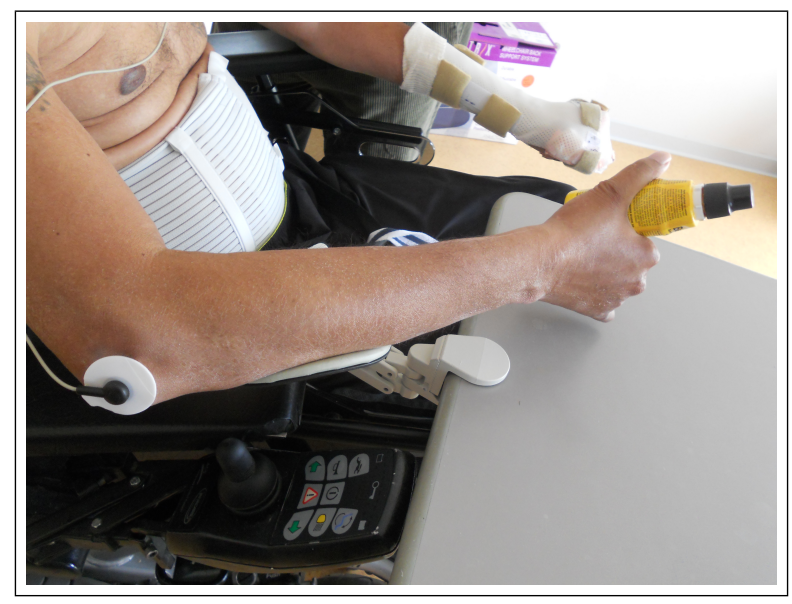

Fig. 1. Upper arm positioning during EMG recording

\section{Methods}

Surface-recording electrodes were positioned above the 4 muscles. The physician or the occupational therapist gives the instructions to execute movements allowing contraction of these muscles. Patients have not received any pre-training before these experiments. The upper arm is sustained by a forearm support (ERGO RESTR), during the procedure and hand fixed around a cylindric object (cf. Fig. 1). Subjects had to perform a contraction as strong as possible of each individual muscle and hold it for 15 seconds. Then, each subject was asked to contract separately each individual muscle and to grade contraction (low, medium and high contraction) holding contraction for 5 seconds for each level of contraction. Visual and/or sound signals encouraged them to contract their muscles. Then, to evaluate proprioception, subjects repeated these same gestures with closed eyes. Tests are carried out on ipsilateral and contralateral sides of the dominant upper limb when possible. Subjects were then asked to choose the most comfortable muscle, i.e. the muscle which is the most easy to contract trying to sustain contraction at 3 different levels.

\section{RESULTS}

Subjects were all able to contract, trapezius, deltoid and platysma muscles. Subject 1 was not able to contract his biceps brachii muscle unlike subjects 2 and 3 (Fig.2, 3, 4, and 5). Each subject was able to contract trapezius, deltoid and platysma continuously for at least one second. They were able to hold 3 distinct amplitudes during the graded contractions of these same muscles, even without visual feedback. For subjects 2 and 3, the maximal and graduated contraction of the 4 muscles was possible. The subjects 1 and 2 reported that the trapezius muscle was the most comfortable to be used as a control signal. The subject 3 having a number of active forearm muscles greater than 2 had no preference.

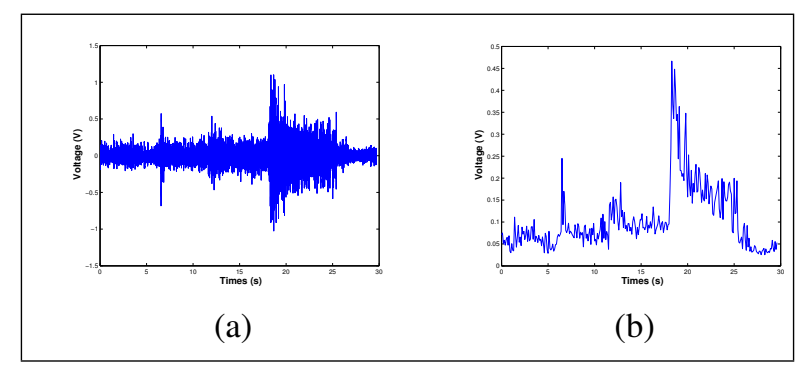

Fig. 2. Graded contraction of the upper trapezius muscle, dominant member, subject 1. (a) Raw signal, (b) RMS signal

We asked subject 1 to perform a graded contraction of his right upper trapezius muscle and hold each contraction for 5 seconds (Fig. 2). The subject could perform a graded contraction but has difficulties to hold it more than 1 second.

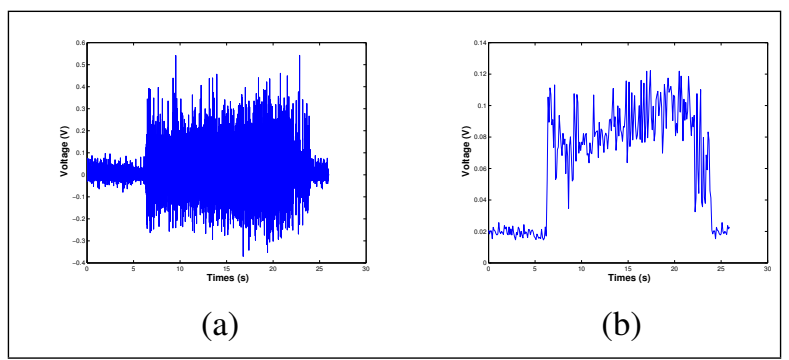

Fig. 3. Peak activation levels of the middle deltoid muscle, dominant member, subject 1. (a) Raw signal, (b) RMS signal

For the trial of Fig. 3 we asked the subject 1 to perform an isometric maximal voluntary contraction of his middle deltoid muscle for $15 \mathrm{~s}$. The subject was able to hold it for 15 seconds. Contraction is clear.

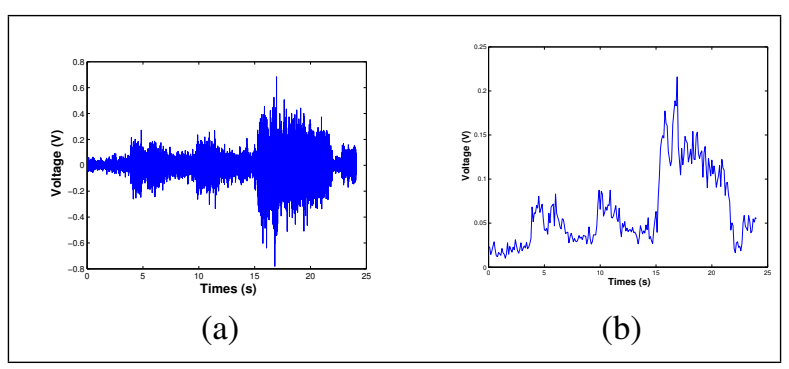

Fig. 4. Graduate contraction of the platysma muscle, dominant member, subject 1. (a) Raw signal, (b) RMS signal

We asked subject 1 to perform an isometric graded contraction of his platysma muscle and hold each contraction for 5 seconds (Fig. 4). The subject could perform a graduated contraction. The power of the EMG signal, shown by the RMS value triple $(53.7 \pm 16.88 \mathrm{mV}$ for the first contraction, $59.83 \pm 14.3 \mathrm{mV}$ for the second contraction, $135.83 \pm 19.4$ $\mathrm{mV}$ for the third contraction) during the contraction but the subject had difficulties to hold it for 5 seconds. 
TABLE I

EMG RMS VALUES FROM MUSCLES OF PATIENT 1, TIME FOR EACH CONTRACTION: 5S

\begin{tabular}{|c|c|c|c|c|c|c|c|c|c|c|c|c|}
\hline \multirow{2}{*}{$\begin{array}{c}\text { Level } \\
\text { of } \\
\text { contraction }\end{array}$} & \multicolumn{3}{|c|}{ upper Trapezius (I) } & \multicolumn{3}{c|}{ middle Deltoid (I) } & \multicolumn{3}{c|}{ Biceps (I) } & \multicolumn{3}{c|}{ Platysma (I) } \\
\cline { 2 - 12 } & $\begin{array}{c}\text { Average } \\
(\mathrm{mV})\end{array}$ & $\begin{array}{c}\text { STD } \\
(\mathrm{mV})\end{array}$ & $\begin{array}{c}\text { Normalised } \\
\text { value }(\%)\end{array}$ & $\begin{array}{c}\text { Average } \\
\mathrm{mV})\end{array}$ & $\begin{array}{c}\text { STD } \\
(\mathrm{mV})\end{array}$ & $\begin{array}{c}\text { Normalised } \\
\text { value }(\%)\end{array}$ & $\begin{array}{c}\text { Average } \\
(\mathrm{mV})\end{array}$ & $\begin{array}{c}\text { STD } \\
(\mathrm{mV})\end{array}$ & $\begin{array}{c}\text { Normalised } \\
\text { value }(\%)\end{array}$ & $\begin{array}{c}\text { Average } \\
\mathrm{mV})\end{array}$ & $\begin{array}{c}\text { STD } \\
(\mathrm{mV})\end{array}$ & $\begin{array}{c}\text { Normalised } \\
\text { value }(\%)\end{array}$ \\
\hline 1 & 75.33 & 18.87 & 0.32 & 72.93 & 9.51 & 0.6 & NA & NA & NA & 53.7 & 16.88 & 0.39 \\
2 & 104 & 12.9 & 0.44 & 84.53 & 10.53 & 0.69 & NA & NA & NA & 59.83 & 14.3 & 0.44 \\
3 & 237 & 59.9 & 1 & 122.13 & 12.87 & 1 & NA & NA & NA & 135.83 & 19.4 & 1 \\
\hline
\end{tabular}

TABLE II

FOUR BEST EMG RMS VALUES FROM MUSCLES OF PATIENT 2, TIME FOR EACH CONTRACTION : 5S

\begin{tabular}{|c|c|c|c|c|c|c|c|c|c|c|c|c|}
\hline \multirow{2}{*}{$\begin{array}{c}\text { Level } \\
\text { of } \\
\text { contraction }\end{array}$} & \multicolumn{3}{|c|}{ upper Trapezius (I) } & \multicolumn{3}{|c|}{ middle Deltoid $(\mathrm{C})$} & \multicolumn{3}{|c|}{ Biceps $(\mathrm{C})$} & \multicolumn{3}{|c|}{ Platysma (I) } \\
\hline & $\begin{array}{c}\text { Average } \\
(\mathrm{mV})\end{array}$ & $\begin{array}{l}\text { STD } \\
(\mathrm{mV})\end{array}$ & $\begin{array}{c}\text { Normalised } \\
\text { value }(\%)\end{array}$ & $\begin{array}{c}\text { Average } \\
\mathrm{mV})\end{array}$ & $\begin{array}{l}\text { STD } \\
(\mathrm{mV}) \\
\end{array}$ & $\begin{array}{c}\text { Normalised } \\
\text { value }(\%)\end{array}$ & \begin{tabular}{|c}
$\begin{array}{c}\text { Average } \\
(\mathrm{mV})\end{array}$ \\
\end{tabular} & $\begin{array}{l}\text { STD } \\
(\mathrm{mV})\end{array}$ & $\begin{array}{c}\text { Normalised } \\
\text { value }(\%)\end{array}$ & $\begin{array}{c}\text { Average } \\
\mathrm{mV})\end{array}$ & \begin{tabular}{|l|} 
STD \\
$(\mathrm{mV})$ \\
\end{tabular} & $\begin{array}{c}\text { Normalised } \\
\text { value }(\%)\end{array}$ \\
\hline 1 & 50.94 & 7.81 & 0.22 & 273.3 & 59.9 & 0.52 & 110.9 & 8.07 & 0.39 & 73.7 & 2 & 0.35 \\
\hline 2 & 96.36 & 3.87 & 0.42 & 370 & 73.2 & 0.71 & 164.8 & 30.8 & 0.58 & 157.5 & 14.5 & 0.74 \\
\hline 3 & 226.97 & 211.51 & 1 & 522 & 61.1 & 1 & 285.8 & 50.5 & 1 & 213 & 51.6 & 1 \\
\hline
\end{tabular}

TABLE III

EMG RMS VALUES FROM MUSCLES OF PATIENT 3, TIME FOR EACH CONTRACTION : 5S

\begin{tabular}{|c|c|c|c|c|c|c|c|c|c|c|c|c|}
\hline \multirow{2}{*}{$\begin{array}{c}\text { Level } \\
\text { of } \\
\text { contraction }\end{array}$} & \multicolumn{3}{|c|}{ upper Trapezius (I) } & \multicolumn{3}{c|}{ middle Deltoid (I) } & \multicolumn{3}{c|}{ Biceps (I) } & \multicolumn{3}{c|}{ Platysma (I) } \\
\cline { 2 - 12 } & $\begin{array}{c}\text { Average } \\
(\mathrm{mV})\end{array}$ & $\begin{array}{c}\text { STD } \\
(\mathrm{mV})\end{array}$ & $\begin{array}{c}\text { Normalised } \\
\text { value }(\%)\end{array}$ & $\begin{array}{c}\text { Average } \\
\mathrm{mV})\end{array}$ & $\begin{array}{c}\text { STD } \\
(\mathrm{mV})\end{array}$ & $\begin{array}{c}\text { Normalised } \\
\text { value }(\%)\end{array}$ & $\begin{array}{c}\text { Average } \\
(\mathrm{mV})\end{array}$ & $\begin{array}{c}\text { STD } \\
(\mathrm{mV})\end{array}$ & $\begin{array}{c}\text { Normalised } \\
\text { value }(\%)\end{array}$ & $\begin{array}{c}\text { Average } \\
\mathrm{mV})\end{array}$ & $\begin{array}{c}\text { STD } \\
(\mathrm{mV})\end{array}$ & $\begin{array}{c}\text { Normalised } \\
\text { value }(\%)\end{array}$ \\
\hline 1 & 53.93 & 19.32 & 0.29 & 85.42 & 5 & 0.25 & 21.38 & 6.39 & 0.37 & 42.5 & 11.19 & 0.30 \\
2 & 116.32 & 38.11 & 0.63 & 185 & 33.75 & 0.54 & 41.5 & 8.74 & 0.72 & 100 & 15.11 & 0.70 \\
3 & 185 & 56.05 & 1 & 345 & 72.25 & 1 & 57.38 & 10.21 & 1 & 143.61 & 32.58 & 1 \\
\hline
\end{tabular}

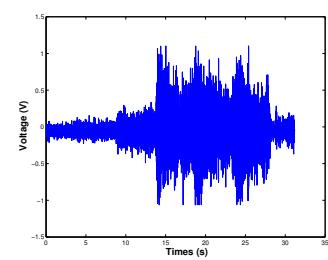

(a)

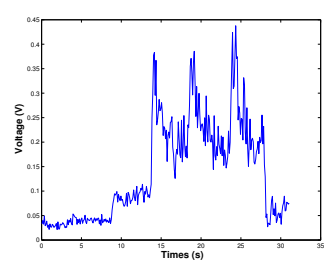

(b)
Fig. 5. Graded contraction of the upper trapezius muscle, dominant member, subject 2. (a) Raw signal, (b) RMS signal

We asked subject 2 to perform an isometric graded contraction of his right upper trapezius muscle and hold each contraction for 5 seconds (Fig. 5). The subject could achieve a graded contraction but had difficulties to hold the third contraction for 5 seconds.

Numerical results are presented in tables II II III (I: ipsilateral, C: contralateral). The 3 levels of contraction are clearly visible for all muscles for the patients 2 and 3 . Indeed, for each level of contraction EMG signal increases by at least 20\%. Distinction between levels 1 and 2 for patient 1 is almost impossible; for instance, the average value for the middle deltoid increases by $15 \%$ (from $72.93 \pm 9.51$ for level 1 of contraction to $84.53 \pm 10.53 \mathrm{mV}$ for level 2 of contraction). Moreover, he failed to contract biceps.

\section{Discussion}

This study enabled us to target potential control strategies and to assess the relevance of using myoelectric signals in quadriplegic patients as a possible discrete control mean for future assistive devices. Our preliminary results show that myoelectric activity of muscles under voluntary control could be used to drive a FES or prosthetic hand with a limited number of contraction levels (3). The use of these different levels of contraction can be either to select a hand function or a different level of torques. 3 of the 4 muscles tested here, both on ipsi- and contralateral sides, could serve as interface for the control of assistive devices. The biceps brachii does not seem adaptated to be used for subject 1 . We have not recorded in our study any electrical activity from under lesional muscles unlike in [8] where authors observed electrical activity in sub lesional muscles in the lower limb in complete paraplegic subjects. Nevertheless, we cannot exclude that it is not present. Indeed, activity from forearm muscles is not very important compared to the muscles of the lower limb, particularly when using surface electrodes.

Strong STD refers to patients who were not able to hold contraction at a stable level, or even worst during 5s. Patient 2 was unable to achieve a correct stable contraction for third level with his upper trapezius making this muscle not a good target for the intended purpose. Finally, given that 
placement of electrodes for each subject is different and the medical assessment is also different, a comparison of the power developed by inter- and intra-individual muscles is irrelevant. The more a muscle is proximal, the more it will likely be controllable by the subject. Selection of muscles to be used for assistive device control has to be decided according to the subjects level of injury and remaining capacities. The 3 subjects were able to hold 3 distinct levels during the graded muscle contraction. Subjects were able to grade their muscle contractions and hold it for at least $1 \mathrm{sec}$. This duration sounds sufficient to assess a voluntary contraction and to processed the signal in order to induce a response (for instance, trigging of an hand opening or closing). Subjects are also able to contract and grade their contraction when they close their eyes. This observation proves that they are able to position their upper limbs in space (proprioception). In the presented trials, only a single contraction of the trapezius muscles, deltoid, biceps and platysma was requested. A subsequent study will help us to determine if subjects are able to contract voluntarily two or more muscles simultaneously. Thus, if the subject can perform both individual and simultaneous contractions of two or more muscles, it may be possible to generate another function mode. For instance, contraction of the deltoid only could allow the opening of the hand while contraction of the trapezius could allow its closure. The simultaneous contraction of both these muscles could allow to move from a palmar grasp to a lateral grasp and vice versa. Thus, each individual could produce several movements from a limited number of active muscles. In case where a co-contraction is not possible or acceptable for the subject, the subject's ability to grade his contraction can be used instead.

\section{CONCLUSION}

EMG signals from sus-lesional muscles could allow complete quadriplegic subjects to control an assistive device for hand motion rehabilitation with a limited number of states that may refer either to few torque level of a given movement (in open loop mode) or selection of a movement among a small set of predefined functions. An EMG-based interface appears to be a solution to achieve this type of control motion in a comfortable manner.

\section{ACKNOWLEDGEMENTS}

The authors wish to thanks the subjects who invested time in this research, Mrs. Sonia Henkous, occupational therapist for her help in this study and Axonic / ANRT support the PhD grant, CIFRE N2013/0867

\section{REFERENCES}

[1] K. D. Anderson, "Targeting recovery: priorities of the spinal cordinjured population," Journal of neurotrauma, vol. 21, no. 10, pp. 1371$1383,2004$.

[2] P. Krause, J. Szecsi, and A. Straube, "Changes in spastic muscle tone increase in patients with spinal cord injury using functional electrical stimulation and passive leg movements," linical rehabilitation, vol. 22, no. 7, pp. 627-634, 2008.
[3] N. Bhadra, P. H. Peckham, M. W. Keith, K. L. Kilgore, F. Montague, M. Gazdik, and T. Stage, "Implementation of an implantable joint-angle transducer," Journal of rehabilitation research and development, vol. 39, no. 3, pp. 411-422, 2002.

[4] T. Keller, A. Curt, M. R. Popovic, A. Signer, and V. Dietz, "Grasping in high lesioned tetraplegic subjects using the emg controlled neuroprosthesis," NeuroRehabilitation-An Interdisciplinary Journal, vol. 10, no. 3, pp. 251-256, 1998.

[5] R. Thorsen, D. Dalla Costa, S. Chiaramonte, L. Binda, E. Beghi, T. Redaelli, E. Occhi, and M. Ferrarin, "A noninvasive neuroprosthesis augments hand grasp force in individuals with cervical spinal cord injury: The functional and therapeutic effects," The Scientific World Journal, vol. 2013, 2013.

[6] W. D. Memberg, K. H. Polasek, R. L. Hart, A. M. Bryden, K. L. Kilgore, G. A. Nemunaitis, H. A. Hoyen, M. W. Keith, and R. F. Kirsch, "Implanted neuroprosthesis for restoring arm and hand function in people with high level tetraplegia," Archives of physical medicine and rehabilitation, vol. 95, no. 6, pp. 1201-1211, 2014.

[7] M. DiCicco, L. Lucas, and Y. Matsuoka, "Comparison of control strategies for an emg controlled orthotic exoskeleton for the hand," in Robotics and Automation, 2004. Proceedings. ICRA'04. 2004 IEEE International Conference on, vol. 2. IEEE, 2004, pp. 1622-1627.

[8] C. W. Moss, K. L. Kilgore, and P. H. Peckham, "A novel command signal for motor neuroprosthetic control," Neurorehabilitation and neural repair, vol. 25, no. 9, pp. 847-854, 2011. 